\title{
Consolidation of Memory for Odor-Reward Association: $\beta$-Adrenergic Receptor Involvement in the Late Phase
}

\author{
Susan J. Sara, ${ }^{1}$ Pascal Roullet, and Jean Przybyslawski \\ Institut des Neurosciences \\ ${ }^{1}$ Centre National de la Recherche Scientifique (CNRS UMR 7624) \\ Université Pierre et Marie Curie \\ 75005 Paris, France
}

\section{Abstract}

Experimentally naive rats can learn rapidly to discriminate among three odors to obtain food reinforcement. After three massed trials, they show almost errorless performance. This task has proved to be useful in studying time-dependent postacquisition intracellular processes necessary for long-term memory. The present experiments evaluated the temporal dynamics of the role of $\beta$-noradrenergic receptors in long-term consolidation. Rats were implanted with intracerebroventricular cannulae and trained in a single session to find reinforcement in a hole in a sponge impregnated with a particular odor. Injections of the $\beta$-receptor antagonist timolol were made at $5 \mathrm{~min}, 1,2$, or $5 \mathrm{hr}$ after training. Memory and relearning ability were evaluated 48 hr later. Rats treated with timolol $2 \mathrm{hr}$ after training showed a memory deficit at the retention test, but were able to relearn the task normally. Injections at the earlier or later time points were ineffective. The results reinforce previous observations with systemic injections that $\beta$-noradrenergic receptors are involved in the late phase of memory consolidation and suggest a critical time window during which they are necessary. The time window is compatible with the current view that long-term memory depends on late involvement of the cAMP cascade leading to new protein synthesis necessary for synaptic reorganization.

${ }^{1}$ Corresponding author.

\section{Introduction}

It has been known for more than a century from clinical studies of retrograde amnesia that memory consolidates slowly over time. Animal models of experimental amnesia have shown that these time-dependent processes involve dynamic interaction between different brain regions and a myriad of intracellular biochemical events. Although these studies have not really produced any consensus concerning the duration of consolidation processes, it is generally agreed that memory formation involves at least two phases-a shortterm transient phase, lasting $\sim 3 \mathrm{hr}$ and a long-term phase, requiring new protein synthesis. This has been revealed through studies using antibiotics to inhibit protein synthesis at the time of training and in the hours after the acquisition. Animals are able to express memory for a period of $\sim 3 \mathrm{hr}$ after learning, but did not have long-term memory when tested the next day (Barondes and Cohen 1966; for review, see Davis and Squire 1984).

New protein synthesis is also necessary for the enduring synaptic plasticity elicited by long-term potentiation (LTP) protocols (Fifkova et al. 1982; Stanton and Sarvey 1986; Otani et al. 1989) and great advances have been made in delineating the intracellular cascade of events on which this protein synthesis-dependent enduring LTP depends (Stanton and Sarvey 1986; Frey et al. 1993). Although unequivocal evidence establishing LTP as the mechanism by which the brain stores information is sparse (Barnes 1995; Eichenbaum 1995; Stevens 1998), LTP as a model system of synaptic plasticity has proved of great heuristic value in hypothesizing cellular mechanisms underlying longterm memory, facilitating the determination by direct behavioral experiments, of intracellular events related to memory processes. In particular, the role

LEARNING \& MEMORY 6:88-96 @ 1999 by Cold Spring Harbor Laboratory Press ISSN1072-0502/99 \$5.00

$$
\begin{array}{llllllllllllllll}
L & E & A & R & N & I & N & G & \boldsymbol{\bigotimes} \\
\mathbf{8 8} & & & & & & & & & &
\end{array}
$$


of the cAMP-PKA (protein kinase $\underline{\mathrm{A}}$ ) cascade, essential for the maintenance of LTP (Stanton and Sarvey 1985a; Abel et al. 1997) has been shown to be necessary for the establishment of long-term memory. These behavioral studies have for the most part used single trial avoidance learning (for review, see Rose 1995; Izquierdo and Medina 1997) or, more recently, contextual fear conditioning (Bourtchuladze et al. 1994; Impey et al. 1998). Because the understanding of the temporal dynamics of the intracellular events occurring subsequent to the learning event is a major objective of these studies, these rapidly learned behavioral tasks are essential in pinpointing the time of the learning event. On the other hand, fear conditioning and avoidance training involve exposing the animal to aversive stimuli, such as electric shock or bitter tastes, raising the question of whether the importance of the cAMP cascade is limited to or particularly important in learning involving stress. We have developed an odor-reward association task for the rat that involves a minimum of stress, is rapidly acquired in a single session, and well remembered over several days. The task has proved useful in confirming the general role of neural cell adhesion molecules (NCAMs) in the stabilizing of long-term memory in the rat (Roullet et al. 1997).

In the experiments reported here, we use this task to plot the temporal dynamics of involvement of the $\beta$-noradrenergic receptor in long-term memory formation. $\beta$-Noradrenergic receptors are part of a family of adenylate cyclase-linked, $G$ protein dependent receptors and as such, are linked positively to the cAMP cascade. Their role in LTP is well established; pharmacological blockade of $\beta$-receptors can prevent the establishment of LTP and application of $\beta$-receptor agonists can induce LTP in the hippocampus on its own (Lacaille and Harley 1985; Huang and Kandel 1996). At the behavioral level, there is some evidence for the involvement of $\beta$-receptors in memory in rats and humans, but the evidence has been confined mostly to procedures involving emotional memories (Cahill et al. 1994). The present study evaluates the role of $\beta$-receptors in the formation of long-term memory for nonstressful odor-reward association. By treating rats with a $\beta$-receptor antagonist at different intervals after learning, and using intracerebroventricellular (ICV) injections, the experiment attempts to determine whether there is a critical time window when the $\beta$-receptor is important or essential to the establishment of long-term memory.

\section{Materials and Methods}

\section{ANIMALS}

Seventy-four Sprague-Dawley rats obtained from IFFA-Credo were used in this experiment. They weighed $220 \mathrm{~g}$ upon arrival in the laboratory and were housed by pairs in plastic cages with wire mesh floors in a temperature- and light-controlled vivarium. Lights were on from 8 a.m. until 8 p.m. and experiments were carried out between 10 a.m. and 5 p.m. Rats were weighed and handled daily from the day of their arrival in the laboratory. There was free access to food and water except during the pretraining, training, and test days, when food was restricted to 20-25 grams/rat per day, to maintain body weight at $\sim 90 \%$ of freely feeding weight.

\section{SURGERY}

One week after arrival in the laboratory rats were implanted with bilateral ICV cannulae under pentobarbital anesthesia $(60 \mathrm{mg} / \mathrm{kg})$. Cannulae were constructed from 24-gauge stainless-steel tubes cut to $11-\mathrm{mm}$ length. They were premounted in pairs $4 \mathrm{~mm}$ apart and held in place by dental cement. Rats were mounted in a stereotaxic apparatus with the head level and holes were drilled over the lateral ventricles $(1 \mathrm{~mm}$ posterior to bregma and $2 \mathrm{~mm}$ lateral to the midline).

Three other holes were drilled to accommodate small screws that served to anchor the dental cement. The cannula assembly was lowered into the brain to a depth of $3 \mathrm{~mm}$ below the surface of the skull. A thin stainless-steel wire was inserted inside each cannula to prevent blockage. The cannulae were cemented in place, the wound treated with antiseptic powder, and closed with a wound clip, if necessary.

\section{PHARMACOLOGICAL TREATMENT}

Injection cannulae were constructed from 36gauge stainless-steel tubing cut to $20-\mathrm{mm}$ length. The tube was inserted into a 24-gauge cannula so that exactly $12 \mathrm{~mm}$ protruded and was glued in place. The larger tube was inserted into a catheter, which was attached to a $10-\mu$ l Hamilton syringe. The thin wire was removed from the ICV cannula and replaced by the injection cannula, which was inserted to a depth of $12 \mathrm{~mm}$ (i.e., $1 \mathrm{~mm}$ below the edge of the guide cannula). The injection was

$$
\begin{array}{llllllllllllllll}
L & E & A & R & N & I & N & G & \boldsymbol{\bigotimes} \\
\mathbf{8 9} & M & E & M & O & R & Y
\end{array}
$$


given over a period of $2-3$ min while the rat was held gently in the hand of the experimenter with minimal of restraint. This injection was then repeated on the other side. Injection volumes were 4 $\mu$ per side. Control rats were injected with sterile saline and the experimental group, with timolol at a concentration of $5 \mu \mathrm{g} / \mu \mathrm{l}$.

\section{APPARATUS}

The training apparatus was a square box constructed of opaque plastic measuring $40 \times 46 \times 24$ $\mathrm{cm}$. Sponges measuring $7 \times 6 \times 2 \mathrm{~cm}$ deep had a hole of $2 \mathrm{~cm}$ in diameter cut into the center and were placed in glass side-holders of the same size. The food reinforcement was placed at the bottom of the opening in the sponge so the rat had to put its head inside the hole (nose poke) to obtain the reward-chocolate rice crispy breakfast food (Chocopops, Kellog's, France). On the first trial, four Chocopops were also placed on the corners of that sponge, which was impregnated with the target odor, as well as in the hole. The sponges with nontarget odors did not contain food. Sponges were placed in three corners of the box and the position of each odor within the box was changed for each trial according to a previously determined protocol. The actual sets of sponges were changed between trials as well to preclude any identification based on visual cues. Sponges were impregnated with an odor by placing $15 \mu \mathrm{l}$ of essence on each corner of the sponge. Odors used were coffee, lemon, and mint, with the rewarded odor being randomly assigned to different rats. A video camera was fixed above the apparatus and the rat was observed on a video monitor in the same room. The session was also recorded on video tape for possible reanalyses off-line.

\section{EXPERIMENTAL DESIGN AND BEHAVIORAL PROCEDURES}

Rats were allowed to recover from surgery for 1 week. They were handled and weighed daily during this recovery period. Food restriction began the day before the first pretraining session. The purpose of the pretraining was to familiarize the rats with the Chocopops used as reinforcement during training. Rats were given free access to this food for $20 \mathrm{~min}$ in a neutral cage during two daily sessions. The first session was shared with the cage mate and at the second session the rat was alone.
Training was carried out in a single session; cage mates were trained during the same session. They were kept in the experimental room in a holding cage and one rat was introduced into the behavioral apparatus, in the corner without a sponge, head toward the wall. A 5-min ceiling was imposed for the rat to find and consume the reinforcement. The rat was removed from the apparatus when it had consumed the Chocopops at the edge of the sponge and had performed an unambiguous nose-poke response and consumed Chocopops from the hole in the center of the sponge. The second rat was then submitted to the first training trial. Intertrial intervals were a minimum of $2 \mathrm{~min}$ and a maximum of $5 \mathrm{~min}$. The spatial configuration of the sponges was changed between trials and the reinforcement was confined to the bottom of the hole and thus no longer visible to the rat. The reinforcement was always associated with the same odor.

Each rat was submitted to three training trials, because previous experiments had shown that most rats had errorless performance after three trials, although they were not at an asymptotic performance in terms of latency to nose poke. Rats that did not nose-poke within $2 \mathrm{~min}$ at the third trial were eliminated from the experiment $(n=4)$

Animals were assigned to treatment groups according to their performance during training in an attempt to avoid any pretreatment differences between groups. Rats were injected with saline, 5 $\min (n=8), 1 \mathrm{hr}(n=11), 2 \mathrm{hr}(n=8)$, or $5 \mathrm{hr}$ $(n=7)$, or timolol, $5 \mathrm{~min}(n=9), 1 \mathrm{hr}(n=12), 2$ hr $(n=7), 5 \mathrm{hr}(n=8)$, after training. During the training-to-injection interval the rats were returned to their home cage. The injection took place in a quiet room, different from the experimental room, as described above.

\section{RETENTION TEST}

Forty-eight hours after training, rats were tested for retention and relearning ability using the same procedure as during training, except that the first test trial was not reinforced and there were a total of four trials. The first two trials were a measure of the memory of the previous training and the last two trials were an index of the rats relearning ability. The behavior was monitored on video and recorded on tape for possible reanalysis. Nose pokes were scored by an observer who was blind to the treatment groups.

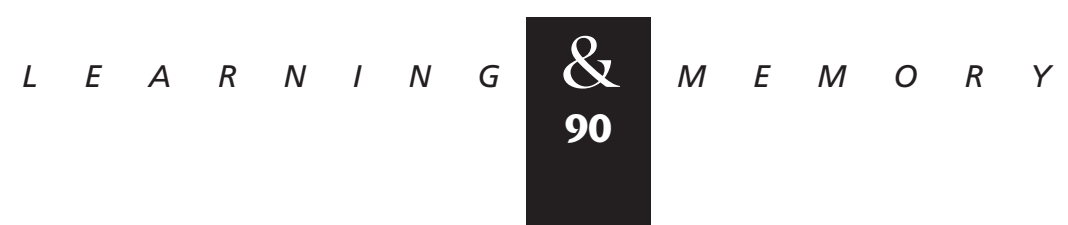




\section{CONTROL FOR CANNULAE PLACEMENT}

On the day following the test rats were injected with angiotensin (200 ng/2 $\mu$ l per side; Angiotensin II, Sigma), placed in an observation cage with a drinking bottle readily available and were observed for latency to drink. Rats that drank within 2 min were considered to have correct cannulae placements. In one replication, rats were anesthetized with an overdose received ICV injections of methyl blue, brains removed, and examined for the presence of blue in the third ventricle. Using either method of verification, all rats had correctly placed cannulae.

\section{DATA ANALYSIS}

Latency to nose poke and number of errors (nose pokes into incorrect sponges) were taken as the performance measure. The experiment was run in three replications. Acquisition scores for the entire data set, in terms of latencies and errors, were submitted to an analysis of variance for repeated measures (ANOVA). There was no effect of replication; therefore the data were pooled for subsequent analysis.

Test scores for each rat were averaged for the two retention trials and the two relearning trials and the data were submitted to a $2 \times 4 \times 2$ ANOVA with a repeated measure (test and retraining) on one factor. The two other independent factors were drug treatment and training-treatment delay ( $5 \mathrm{~min}, 1 \mathrm{hr}, 2 \mathrm{hr}$, or $5 \mathrm{hr}$ ). ANOVA was complemented by planned comparisons using the TukeyKramer procedure.

\section{Results}

\section{TASK ACQUISITION}

On the first trial rats engaged in much investigation of the experimental environment and sniffing at the sponges. The rat usually consumed the reinforcement visible on the edge of the sponge as soon as it was encountered. It took as long as $5 \mathrm{~min}$ for some rats to nose poke into the correct sponge and consume the reinforcement. On the second trial, many rats returned to the place where they were reinforced on the first trial, before investigating the other sponges. On the third trial there was a significant decrease in latency to find the correct sponge and make the nose-poke response, as can be seen in Figure 1A. The rats sniffed the edges of
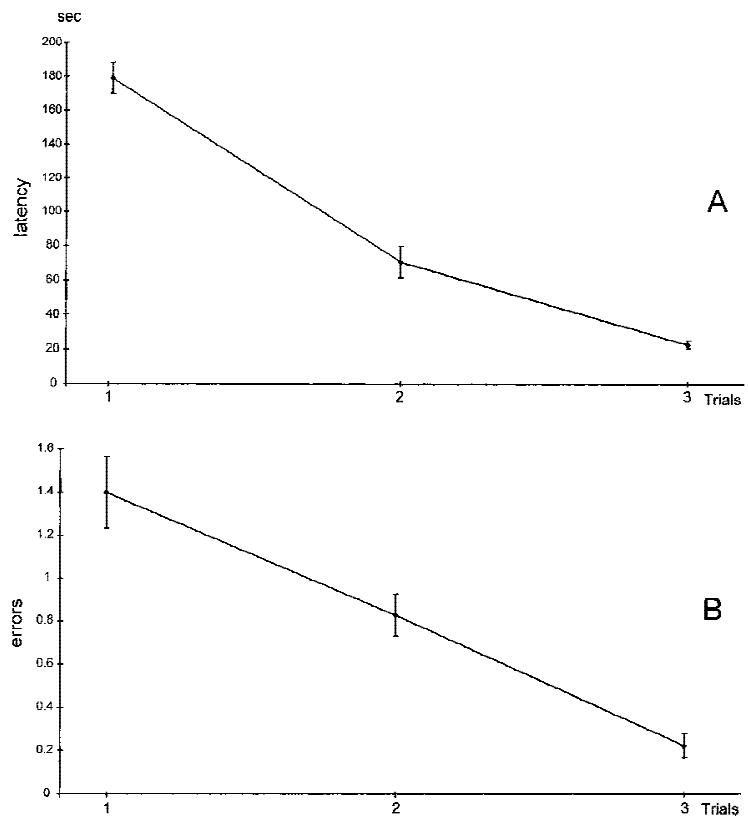

Figure 1: Acquisition of odor-reward association. (A) Latency to make the nose-poke response to the target odor. (B) Errors during acquisition trials. An error was scored when the rat made a nose-poke into a nonreinforced hole. There was a significant decrease in the time to emit the nose-poke response and consume the reinforcement over the three trials and a significant decrease in the number of errors. Most rats had an errorless performance at the third trial.

the sponges and rarely made a nose poke (error) to a nontarget odor. Thus, by the third trial errors rarely occurred (Fig. 1B).

\section{TEST AND RETRAINING}

The mean latency for each treatment group on the two test trials and on the two retraining trials can be seen in Figure 2. A three-way ANOVA for repeated measures was applied to these data, one factor being drug treatment, one factor being time of injection, and the repeated factor being the test and retraining. There was a significant effect of drug $\left(F_{1,69}=5.75, P=0.02\right)$, a significant effect of time interval post-training $\left(F_{3,69}=17.6\right.$; $P<0.0001), \quad$ a significant repetition effect $\left(F_{1,70}=24.9 ; P<0.0001\right)$, and most important, a significant drug $\times$ injection time $\times$ repetition interaction $\left(F_{3,62}=8.62 ; P<0.0001\right)$. Planned orthogonal comparisons using the Tukey-Kramer procedure revealed a significant difference between saline and timolol 2-hr groups at the test trial. The

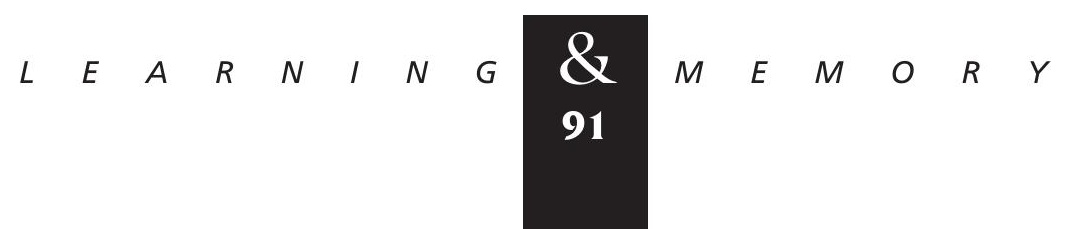


Sara et al.

Figure 2: Latency for correct response, which was a nose-poke into sponge with the reinforced odor. Independent groups were treated at $5 \mathrm{~min}, 1,2$, or $5 \mathrm{hr}$ after training with saline (solid lines) or timolol (dotted lines). ( $\mathrm{T}$ ) test score; (R) retraining score. Testing and retraining took place in a single session, $48 \mathrm{hr}$ after initial training. $(*)$ Significantly different from the saline control group; $(\mathbf{O})$ different from timolol $5 \mathrm{~min}$; $1 \mathrm{hr}$ and $(\bullet)$ 5 hr groups (all $P<0.01$ ). There were no other significant orthogonal comparisons.
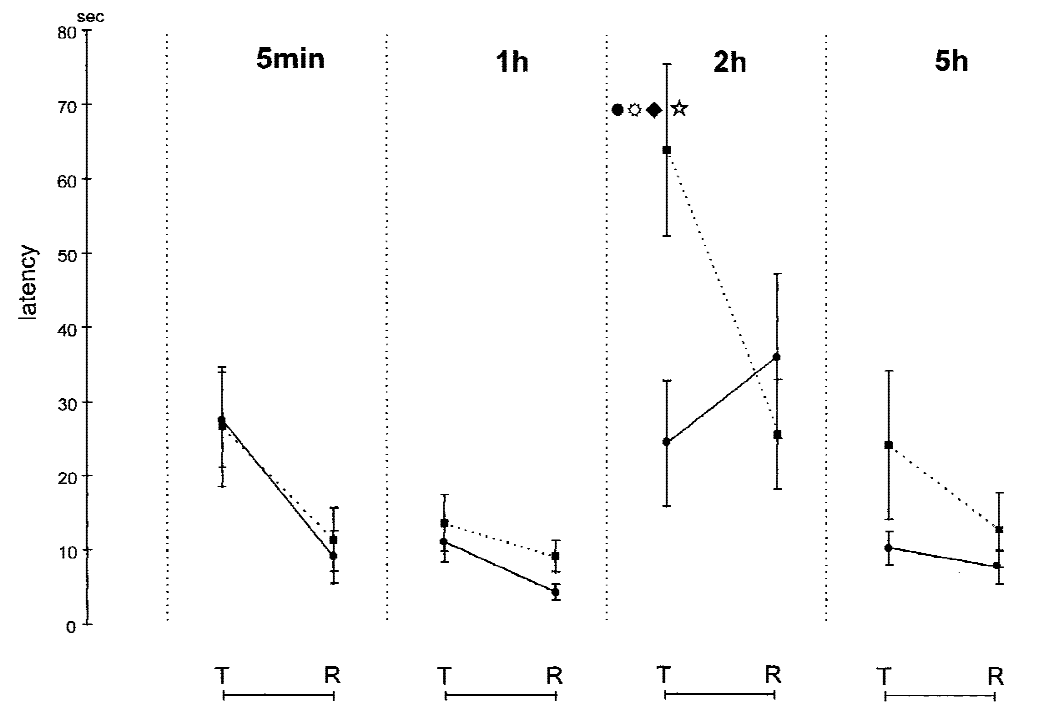

timolol 2-hr group was significantly different from the other three timolol groups, as well (all $P<0.01)$. There were no significant differences between groups for any other injection time for either the saline or timolol groups. The timolol 2-hr group showed significant improvement at retraining compared to its own test performance $(P<0.01)$.

A similar pattern of results is seen when errors are considered as the performance measure. The mean of the two test trials and the two retraining trials is shown in Figure 3. The data were analyzed as described above for latencies. Here there was a significant main effect on the repetition factor $\left(F_{1,70}=5.27 ; P=0.02\right)$, and a highly significant drug $\times$ repetition interaction $\left(F_{1,69}=12.55\right.$;

$P=0.0008)$, as well as a drug $\times$ time of injection $\times$ repetition interaction $\quad\left(F_{3,62}=5.35\right.$; $P=0.002)$. Planned orthogonal comparisons revealed that the timolol 2 -hr group made significantly more errors at the test than all other timolol groups and significantly more errors than the saline 2-hr control group. The within-group difference between test and retraining was significant for this group as well $(P<0.05)$. There were no other significant orthogonal comparisons.

\section{Discussion}

\section{LEARNING THE ODOR REWARD ASSOCIATION TASK}

Using the procedure described above, acquisi-

Figure 3: Errors (nose pokes to the nontarget odor) at test $(\mathrm{T})$ and retraining $(\mathrm{R})$ for independent groups treated at $5 \mathrm{~min}, 1,2$, and $5 \mathrm{hr}$ after acquisition, with saline or timolol; test and retraining took place in a single session, $48 \mathrm{hr}$ after initial training. $\left.{ }^{*}\right)$ Significantly different from saline control group; $(\mathbf{O})$ significantly different from $5 \mathrm{~min},(\vdots) 1 \mathrm{hr} ;(\bullet) 5 \mathrm{hr}$ timolol groups $(P<0.01)$. There were no other significant orthogonal comparisons.

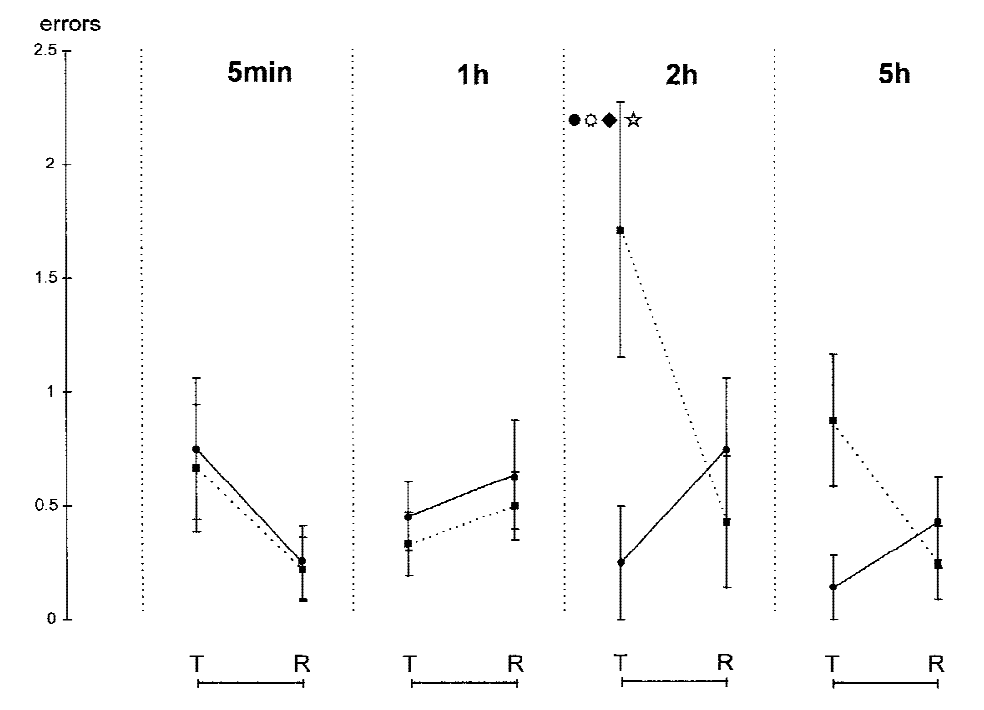

$$
\begin{array}{llllllllllllllll}
\hline & E & A & R & N & I & N & G & \mathbf{Q} \\
92 & M & E & M & 0 & R & Y
\end{array}
$$


tion of the discrimination among three odors was accomplished in only three trials for most rats. After three trials there is almost errorless performance, although there is still room for improvement in terms of latency to respond. Most odor discrimination studies use training procedures involving many more trials and often repeated sessions, even for a discrimination between a single pair of odors. For example, Otto et al. (1991) report that rats require $>200$ trials to learn to discriminate between two odors for water reward and this after a 60 trial pretraining session to learn the operant (nose poke) response. On the other hand, once the rat learns the rule, there is progressive savings as the animal applies it to successive discriminations and the rat has proved to have remarkable capacity to learn and remember long lists of odor pairs (Staubli et al. 1985).

Given the marked difference in the acquisition rate in the present experiment compared with performances obtained in other laboratories using slightly different procedures (Otto et al. 1991; Saar et al. 1998), the behavior observed here merits further description. First, it should be emphasized that the behavioral performance is reliable, even after only three trials, especially in terms of errors. This has been seen in a previous series of experiments in which rats were submitted to five trials, after which they were sacrificed for autoradiography. In those experiments, the rats sustained nearly errorless performance from trial 3 through trial 5 (Roullet et al. 1999). In the present experiments, control rats continued to show errorless performance at retention test $48 \mathrm{hr}$ after the three trial training. Comparing the behavior after three trials to that of an overtrained rat, qualitative differences can be noted. On the first trial, rats explore randomly and consume the reinforcement when it is encountered. On the second trial, most animals return to the place within the box where the sponge containing the reinforcement had been on the previous trial. By the third trial they sniff the sponges until they encounter the odor associated with the reinforcement and then search in the hole for the Chocopop. This usually involves sniffing all three sponges and returning to the target odor. By the fourth or fifth trial, most rats detect the location of the odor from the start point in the box and go directly to that sponge to nose poke and consume the reinforcement. Thus, there is an improvement in performance in terms of latency.

The reason for the extraordinarily rapid acquisition rate using this procedure compared to others is not clear. In other odor discrimination experiments, rats are water deprived, whereas in the present experiments the rats are only slightly food deprived and receive a very palatable reinforcement, to which they have been habituated beforehand. The rats are handled for 10 days before the experiments. These procedures assure a minimum of stress during the experiment. The response of nose poking into a sponge is very much a part of the spontaneous behavioral repertoire of a foraging rat, as is sniffing the edges of the sponges in active search; therefore the rat is not required to learn any new behavior, but merely the association between the odor and the food.

\section{RETENTION AND RELEARNING}

This association is well retained over $48 \mathrm{hr}$, as indicated by the good discrimination performance at the retention test. Even in the absence of reinforcement on the first test trial, the rat persists on the next trial to nosepoke in the sponge with the target odor, indicating a durable memory, resistant to extinction by a single nonreinforced trial. Those rats treated with timolol at $5 \mathrm{~min}, 1 \mathrm{hr}$, and $5 \mathrm{hr}$ showed similar robust memory $48 \mathrm{hr}$ later. Only the rats treated at 2-hr post-training displayed amnesia on the test trials. They relearned the task rapidly, assuring that the drug did not impair their ability to make the odor discrimination and perform the consumatory response.

\section{TEMPORAL DYNAMICS OF $\beta$-RECEPTOR ANTAGONIST EFFECT}

The present results indicate that there is a rather precise time window of $\sim 2 \mathrm{hr}$ post-training when $\beta$-receptors are essential for the formation of a long-term memory of the odor-reward association. Previous experiments from our laboratory had suggested a late involvement of $\beta$-receptors in reconsolidation of a reactivated memory for a spatial discrimination. Systemic injections of the $\beta$-receptor antagonist propranolol yielded an extended temporal gradient of efficacy in inducing amnesia, with the intraperitoneal injections being effective at $5 \mathrm{~min}$ but not $5 \mathrm{hr}$ after training (J. Przybyslawski, P. Roullet, and S.J. Sara, in prep.). ICV injections using the same behavioral paradigm revealed a restricted time window of efficacy at $1 \mathrm{hr}$ posttrial (Roullet and Sara 1998). There was no effect of ICV injections made at $5 \mathrm{~min}, 30 \mathrm{~min}$, or $5 \mathrm{hr}$ after

$$
\begin{array}{llllllllllllllll} 
& E & A & R & N & I & N & G & \boldsymbol{Q} \\
93 & M & E & M & O & R & Y
\end{array}
$$


the trial. The 2-hr time point, which proved to be critical in the present experiments, was not tested in the previous studies. In the present experiments, there was no effect of the treatment administered $1 \mathrm{hr}$ after the training. There are major differences between the two sets of experiments that could account for the differences in temporal dynamics of consolidation. The previous experiments used a spatial task that was learned with trials spaced over several days. The rats received a single reactivation trial lasting $<1$ min before drug treatment. The present experiments addressed the question of the role of these $\beta$-receptors in the initial formation of new memories. For this reason the rapidly acquired odor discrimination task was used; nevertheless, the rat required $\sim 12-15 \mathrm{~min}$ to run the three trials. Given these essential differences in protocol-reactivation lasting 1 min versus initial learning lasting $12 \mathrm{~min}$ and differences in cognitive requirements of the tasks-spatial versus odor discrimination, the conclusions derived from the two series of results are unequivocal. $\beta$-Receptors are not necessary for the early stages of postacquisition information processing, but play a role in a later phase of memory consolidation or reconsolidation.

\section{$\beta$-RECEPTORS AND THE CAMP CASCADE}

$\beta$-Noradrenergic receptors are part of a family of adenylate cyclase-linked, G protein-dependent receptors and as such, are positively linked to the cAMP cascade. The results of the present experiments, showing that blockade of these receptors at $2 \mathrm{hr}$ after odor-reward association training, reinforce the current view that long-term memory is dependent on the cAMP cascade, phosphorylation of cAMP response element-binding (CREB) protein, and the resultant new protein synthesis necessary for the synaptic modification underlying memory. The time frame fits well with other data showing that there is a critical time window when cAMP is elevated (Bernabeu et al. 1996) and a critical time window for modification of NCAMs at 5-6 hr after training (Alexinsky et al. 1997; Roullet et al. 1997). Rose and colleagues (1995) have pioneered this approach and have provided an elaborate description of the temporal dynamics of sequential events lasting for hours after acquisition of a simple avoidance task in the day-old chick. In the rat, cAMP is elevated 3-6 hr after single trial avoidance training and the blockade of cAMP is effective in this time window, but not before or after (Bernabeu et al. 1997a). Similar results have been obtained for late involvement of PKA in both rodent and chick (Rose 1995; Abel et al. 1997; Bernabeu et al. 1997b). This intracellular cascade of events presumably results in a new protein synthesis that provides the substance of long-term synaptic facilitation.

That noradrenaline may be one of the possible signals for formation of long-term memory is very plausible given the cognitive context that governs the firing activity of noradrenergic neurons of the locus ceruleus (LC). Recording activity of single units of the LC in the behaving rat, we have observed phasic increases when the rat is exposed to a novel environment (Sara et al. 1994; Sara 1998) and tonic responds in bursts of activity when the rat is exposed to salient novel stimuli (Hervé-Minvielle and Sara 1995; Vankov et al. 1995). When the stimulus is not followed by reinforcement, the LC response habituates rapidly, but as soon as a reinforcement contingency is introduced, the LC cells respond anew. Whenever the stimulus-reinforcement contingency changes, that is, when there is a change in the predictive value of the stimulus, the LC fires in bursts (Sara and Segal 1991). Prolonged action at the $\beta$-receptor, of the norepinephrine released by these bursts of LC neurons would assure the activation of the CAMP-PKA cascade, increasing the probability of long-term memory formation. The question remains as to whether there is a prolonged increase in noradrenergic activity lasting up to $2 \mathrm{hr}$ after the training or whether there is a rebound of activity occurring $2 \mathrm{hr}$ after the initial learning.

\section{Acknowledgments}

We thank Niara Lucas for technical assistance and Yves Moricard for preparing the figures and help in preparing the manuscript. The odor discrimination task was developed in our laboratory by Russel Phillips. This research was funded by the European Neuroscience Programme of the European Science Foundation and by CNRS UMR 7624.

The publication costs of this article were defrayed in part by payment of page charges. This article must therefore be hereby marked "advertisement" in accordance with 18 USC section 1734 solely to indicate this fact.

\section{References}

Abel, T., P.V. Nguyen, M. Barad, T.A. Deuel, E.R. Kandel, and R. Bourtchouladze. 1997. Genetic demonstration of a role for PKA in the late phase of LTP and in hippocampus-based long-term memory. Cell 88: 615-26.

Alexinsky, T., J. Przybyslawski, R. Mileusnic, S.P.R. Rose, and S.J. Sara. 1997. Antibody to day-old chick brain glycoprotein

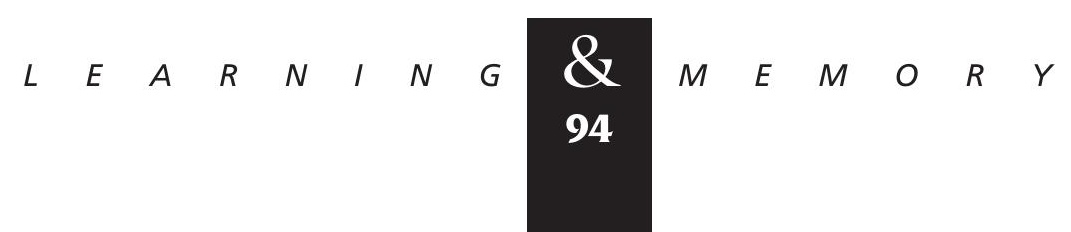


produces amnesia in adult rats. Neurobiol. Learn. Mem. 67: 14-20.

Barnes, C.A. 1995. Involvement of LTP in memory: Are we "searching under the wrong street light." Neuron 15: 751-754.

Barondes, S.H. and H.D. Cohen. 1966. Puromycin effect upon successive phases of memory storage. Science 151: 594-595.

Bernabeu, R., P. Schmitz, M.P. Faillace, I. Izquierdo, and J.H. Medina. 1996. Hippocampal cGMP and cAMP are differentially involved in memory processing of inhibitory avoidance learning. Neuroreport 7: 585-588.

Bernabeu, R., L. Bevilaqua, P. Ardenghi, E. Bromberg, P. Schmitz, M. Bianchin, I. Izquierdo, and J.H. Medina. 1997a. Involvement of hippocampal cAMP/cAMP-dependent protein kinase signaling pathways in a late memory consolidation phase of aversively motivated learning in rats. Proc. Natl. Acad. Sci. 94: 7041-7046.

Bernabeu, R., N. Schroder, J. Quevedo, M. Cammarota, I. Izquierdo, and J.H. Medina. 1997b. Further evidence for the involvement of a hippocampal cGMP/cGMP-dependent protein kinase cascade in memory consolidation. Neuroreport 8: 2221-2224.

Bourtchuladze, R., B. Frenguelli, J. Blendy, D. Cioffi, G. Schutz, and A.J. Silva. 1994. Deficient long-term memory in mice with a targeted mutation of the cAMP-responsive element-binding protein. Cell 79: 59-68.

Cahill, L., B. Prins, M. Weber, and J.L. McGaugh. 1994. Beta adrenergic activation and memory for emotional events. Nature 371: 702-704.

Davis, H.P. and L. Squire. 1984. Protein synthesis and memory: A review. Psychol. Bull. 96: 518-559.

Eichenbaum, H. 1995. Spatial learning-The LTP-memory connection. Nature 378: 131-132.

Fifkova, E., C. Andersen, S. Young, and A. Harreveld. 1982. Effect of anisomycin on stimulation-induced changes in dendritic spines of the dentate granule cells. J. Neurocytol. 11: 183-210.

Frey, U., Y.-Y. Huang, and E. Kandel. 1993. Effects of cAMP simulate a late stage of LTP in hippocampal CA1 neurons. Science 260: 1661-1664.

Hervé-Minvielle, A. and S.J. Sara. 1995. Rapid habituation of auditory responses of locus coeruleus cells in anaesthetized and awake rats. Neuroreport 6: 1235-1240.

Huang, Y.Y. and E.R. Kandel. 1996. Modulation of both the early and the late phase of mossy fiber LTP by the activation of $\beta$-adrenergic receptors. Neuron 16: 611-617.

Impey, S., D.M. Smith, K. Obrietan, R. Donahue, and C. Wade. 1998. Stimulation of cAMP response element
(CRE)-mediated transcription during contextual learning. Nature Neurosci. 1: 595-601.

Izquierdo, I. and J.H. Medina. 1997. The biochemistry of memory formation and its regulation by hormones and neuromodulators. Psychobiology 25: 1-9.

Lacaille, J.C. and C.W. Harley. 1985. The action of norepinephrine in the dentate gyrus: Beta-mediated facilitation of evoked potentials in vitro. Brain Res. 358: $210-220$.

Otani, S., C.J. Marshall, W.P. Tate, G.V. Goddard, and W.C. Abraham. 1989. Maintenance of long-term potentiation in rat dentate gyrus requires protein synthesis but not messenger RNA synthesis immediately post-tetanization. Neuroscience 28: $519-526$.

Otto, T., H. Eichenbaum, G. Lynch, F. Schottler, and U. Staubli. 1991. Hippocampus and olfactory discrimination learning: Effects of entorhinal cortex lesions on olfactory learning and memory in a successive-cue, go-no-go task. Behav. Neurosci. 105: 111-119.

Rose, S.P.R. 1995. Cell-adhesion molecules, glucocorticoids and long-term-memory formation. Trends Neurosci.

18: $502-506$.

Roullet, P. and S.J. Sara. 1998. Consolidation of memory after reactivation: Involvement of $\beta$ noradrenerginic receptors in the late phase. Neural Plasticity 6: 63-68.

Roullet, P., R. Mileusnic, S.P.R. Rose, and S.J. Sara. 1997. Neural cell adhesion molecules play a role in rat memory formation in appetitive as well as aversive tasks. Neuroreport 8: 1907-1911.

Roullet, P., Y. Moricard, R. Bourne, M. Stewart, and S.J. Sara. 1999. Modification of NMDA receptors after learning is region and task specific. Neuroscience 89: 1145-1150.

Saar D., Y. Grossman, and E. Barkai. 1998. Reduced after-hyperpolarization in rat piriform cortex pyramidal neurons is associated with increased learning capability during operant conditioning. Eur. J. Neurosci. 10: $1518-1523$.

Sara, S.J. 1998. Learning by neurones: Role of attention, reinforcement and behaviour. C.R. Acad. Sci. 321: 193-198.

Sara, S.J. and M. Segal. 1991. Plasticity of sensory responses of locus coeruleus neurons in the behaving rat: Implications for cognition. Prog. Brain. Res. 88: 571-585.

Sara, S.J., A. Vankov, and A. Hervé. 1994. Locus coeruleus-evoked responses in behaving rats: A clue to the role of noradrenaline in memory. Brain Res. Bull. 35: 457-465.

Stanton, P.K. and J.M. Sarvey. 1985. The effect of high-frequency electrical stimulation and norepinephrine on cyclic AMP levels in normal versus norepinephrine-depleted rat hippocampal slices. Brain Res. 358: 343-348. 


\section{Sara et al.}

. 1986. Blockade of norepinephrine induced

long-lasting potentiation in the hippocampal dentate gyrus by an inhibitor of protein synthesis. Brain Res. 361: 276-283.

Staubli, U., T.T. Le, and G. Lynch. 1995. Variants of olfactory memory and their dependencies on the hippocampal formation. J. Neurosci. 15: 1162-1171.

Stevens, C.F. 1998. A million dollar question: Does LTP $=$ memory? Neuron 20: $1-2$.

Vankov, A., A. Hervé-Minvielle, and S.J. Sara. 1995.

Response to novelty and its rapid habituation in locus coeruleus neurons of the feely exploring rat. Eur. J. Neurosci. 7: 1180-1187.

Received December 29, 1998; accepted in revised form February 24, 1999. 


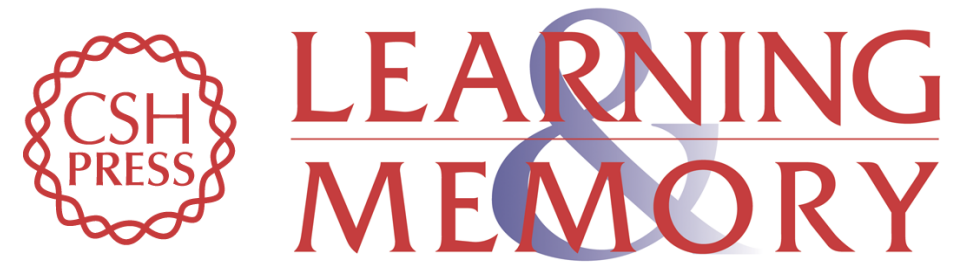

\section{Consolidation of Memory for Odor-Reward Association: $\beta$ -Adrenergic Receptor Involvement in the Late Phase}

Susan J. Sara, Pascal Roullet and Jean Przybyslawski

Learn. Mem. 1999, 6:

Access the most recent version at doi:10.1101/lm.6.2.88

References This article cites 31 articles, 4 of which can be accessed free at: http://learnmem.cshlp.org/content/6/2/88.full.html\#ref-list-1

License

Email Alerting Receive free email alerts when new articles cite this article - sign up in the box at the Service top right corner of the article or click here. 